\title{
Paraparesia espástica progresiva asociada a HTLV-I en Chile: Estudio y seguimiento de 121 pacientes por diez años Progresive spastic paraparesis associated to HTLV-I in Chile
}

Luis Cartier R. ${ }^{1}$

Revision is made to 121 Chilean patients with progressive adult spastic paraparesis (PSPs) associated to HTLV-I. Epidemiologic, clinical, diagnosis and associated illnesses aspects are analyzed as well as the pathogenesis. The follow-up of patients during several years allowed defining the evolutional profile, establishing the causes of death and studying the virus' behavior. Pathogenetic hypothesis arose from the neuropathological search to define the mechanisms of damage supported on immunohystochemical studies. It was confirmed that the CNS illness is a degenerative process linked to a central axonopathy which expresses flaws in the axoplasmic transport, particularly affecting the corticospinal tracts, although there is a more extended myeloencephalic involvement. Furthermore, the virus is capable of producing a multisystemic illness that may simultaneously involve the nervous system; the haemathological system; the exocrine glands; the hepatic, lung, muscular and bone parenchymas.

Key words: Tropical Spastic Paraparesis. HTLV-I. Central axonopathy, Axoplasmic transport. Rev Chil Neuro-Psiquiat 2009; 47 (1): 50-66

\section{Introducción}

$\mathrm{H}$ uman T Lymphotropic virus type I (HTLV-I), fue el primer retrovirus humano, identificado por Poiez y colaboradores en 1980, en un paciente portador de un linfoma $\mathrm{T}^{1}$. Gessain $\mathrm{y}$ cols en 1985, establecieron que el HTLV-I también se encontraba asociado a la Paraparesia Espástica Tropical ${ }^{2}$. En Chile, el HTLV-I fue detectado en 1989, en una serie de pacientes que eran portadores de una paraparesia espástica progresiva $^{3}$.

Los estudios epidemiológicos del virus, realizados en Chile en la década del 90, observaron una seroprevalencia de $0,70 \%$, en la población chilena general ${ }^{4,5}$ y una seroprevalencia mayor, del 1\% al 9\% entre los "pueblos originarios" que sugerían una presencia prehispánica del HTLV-I en Chile y en América ${ }^{6,7}$.

Presuntamente, este retrovirus habría sido

Recibido: 10 de enero de 2009

Aceptado: 20 de marzo de 2009

1 Profesor Titular de Neurología. Facultad de Medicina, Universidad de Chile. 
trasportado desde el Asia por los inmigrantes invasores que cruzaron el estrecho de Bering, trayendo consigo el HTLV-I y el HTLV-II. En oleadas sucesivas, distintos grupos de origen mongoloide y durante dos mil años, fueron poblando el Continente Americano. Curiosamente, los que poblaron las orillas del océano Pacífico desde Alaska a Chiloé y la región andina aledaña, albergaban el HTLV-I. En cambio los portadores del HTLV-II se instalaron en la cuenca de los grandes ríos de Sudamérica (Orinoco, Amazonas, Paraná) y en la costa atlántica, hasta Tierra del Fuego ${ }^{8,9}$.

Li y cols en 1999, demostraron la presencia temprana del HTLV-I en los oasis atacameños. Parte del DNA viral del HTLV-I, se encontró en una momia con más de 1.500 años de antigüe$\mathrm{dad}^{10}$. Esta ancestral presencia del virus en Chile, seguramente permitió el desarrollo de la cepa de HTLV-I, que actualmente se encuentra en las paraparesias espáticas chilenas ${ }^{11}$. Sin embargo, el HTLV-I tiene en el Nuevo Mundo un doble origen, asiático y africano. Los africanos que llegaron a poblar principalmente el Caribe, Centroamérica y Brasil durante los siglos XVI y XVII trajeron consigo las cepas africanas del HTLVI. ${ }^{9,12,13}$.

Es frecuente que la infección por HTLV-I se encuentre en varios miembros de una familia. En los casos de paraparesia espástica la infección entre los cónyuges, habitualmente formado por parejas estables, es del $66 \%$ independiente de quién sea el enfermo. Hemos encontrado que son portadoras de HTLV-I hasta el 44\% de las madres de paraparéticos que hemos podido estudiar. Entre la descendencia de los paraparéticos, la infección afecta al $24 \%$ de las hijas y al $10 \%$ en los hijos. La infección intrafamiliar del HTLV-I permite el desarrollo de formas familiares de paraparesia, donde más de un miembro infectado, padece la enfermedad ${ }^{14,15}$.

Los estudios de seroprevalencia han mostrado cifras variables en otros países ${ }^{16-19}$.

Sólo entre 1 y $2 \%$ de los infectados con HTLV-I tienen la posibilidad de desarrollar una paraparesia. La mayoría permanecen como portado- res sanos. De allí la importancia del control serológico en los bancos de sangre y el necesario estudio de las embarazadas, con el objeto de limitar el amamantamiento, que es un reconocido mecanismo en la propagación del HTLV-I ${ }^{20}$.

La incidencia de paraparesias espásticas asociadas a HTLV-I en Chile, se estima en 2:100.000, cifra que casi triplica la que ostenta Japón, estimada en 0,68: 100.000, aunque ambos países muestran una seroprevalencia próxima al $1 \%$ en su población general ${ }^{5,17}$.

Sólo entre 60 y $80 \%$ de las paraparesias espásticas progresivas son seropositivas para el virus $^{21,22}$. En Chile, establecimos que muchos casos de paraparesias seronegativas, que pudieron atribuirse a otras causas, tenían una reacción de polimerazas (PCR) positiva para el gen tax. Este procedimiento ha resultado indispensable para reconocer como HTLV-I paraparesias seronegativas $^{23}$. Pareciera que en los casos seronegativos tax positivos, el comportamiento del virus y la relación virus-huésped presentan anomalías que hacen posible esta respuesta ${ }^{21}$.

El propósito de esta presentación es la evaluación del comportamiento clínico-biológico de las paraparesias espásticas progresivas, producidas por el retrovirus linfotrópico tipo I, en Chile.

\section{Pacientes y Método}

Método de estudio: Se ha intentado establecer un perfil clínico-evolutivo de la paraparesia espástica asociada a HTLV-I en nuestro medio, basados en el análisis de 121 pacientes estudiados entre los años 1989 y 2005, que mayoritariamente han sido seguidos por más de 10 años en el Servicio de Neurología del Hospital del Salvador (Departamento de Ciencias Neurológicas de la Facultad de Medicina de la Universidad de Chile). En lo clínico, se privilegió el análisis del síndrome motor, evaluando la potencia muscular y condición de la marcha, junto a la vejiga neurogénica y a las características de las llamadas enfermedades asociadas. En lo virológico se identificaron cepas virales y se evaluó el comportamien- 
to del HTLV-I en nuestros pacientes. Los aspectos patogénicos fueron abordados a través de el estudio del líquido cefalorraquideo (LCR), buscando factores que pudieran tener significado causal y desde la histopatología de la médula espinal y cerebro, de pacientes con estudio anatomopatológico.

Como es una enfermedad que se expresa particularmente por la disfunción de las extremidades inferiores, la cuantificación del daño funcional se ha basado en una escala de marcha, definida hace más de 30 años en nuestro Servicio. 1) Marcha sin defecto, síndrome piramidal; 2) Marcha espástica independiente, a) eficiente, b) poco eficiente; 3) Marcha paretoespástica con apoyo, a) eficiente, b) poco eficiente; 4) Bipedestación sin marcha; 5) Postración: a) incapaz de sostenerse, b) compromiso global.

También se estableció una escala para la vejiga neurogénica: 1) Polaquiuria (más de 6 emisiones diurnas y nicturia); 2) Urgencia miccional (necesidad imperiosa de orinar); 3) Incontinencia (pérdida del control del esfínter externo).

\section{Características generales de la muestra}

Los pacientes son originarios de las diferentes Regiones del país. Por la ubicación de nuestro Hospital, el 40\% es de la Región Metropolitana, seguidos con un $12 \%$ de la VIII y IX Regiones respectivamente. La mayoría de los pacientes son fenotipicamente caucasianos, aunque un estudio del genoma mitocondrial, realizado en 30 de ellos, encontró que el 89\% tenía un genoma mitocondrial indígena. Definiendo en la mayoría de ellos un mestizaje.

Ochenta y cinco pacientes son mujeres, $(70,2 \%)$ y treinta y seis son hombres $(29,8 \%)$, estableciendo una relación hombre: mujer de 1 : 2,3. La edad promedio para el comienzo de la enfermedad fue de 45,8 años (17-74 años). El $78,5 \%$ inició su enfermedad en la quinta década. La latencia entre el comienzo de la enfermedad y la consulta en nuestro Servicio fue de 5,5 años en promedio, con un mínimo de cuatro meses y un máximo de veinticinco años.

Aparecieron como factores considerados de riesgo para esta infección el antecedente de cirugías $(16,5 \%)$ y el de transfusiones $(10 \%)$. No se pudieron establecer antecedentes sexuales de riesgo.

La identificación etiológica de la enfermedad incluyó el estudio serológico por ELISA y la confirmación con el estudio de PCR para HTLV-I.

En esta serie también se puso en evidencia la condición esporádica de la enfermedad, aunque se describen formas familiares, que están incluidas en el conjunto. Se consideraron formas familiares, aquellas en que a lo menos dos miembros consanguíneos tenían paraparesia espástica asociada a HTLV-I. También se incluyó un matrimonio, en que ambos cónyuges cursaron con una paraparesia espástica y donde la mujer además era portadora de un linfoma $\mathrm{T}$ crónico.

Desde el punto de vista neuropatológico se pudieron estudiar doce pacientes.

\section{Clínica}

Se estableció que el 70\% de los pacientes iniciaron su enfermedad con alteraciones de la marcha, que es descrita por ellos como debilidad, o sensación de pesadez o tirantez de una o ambas piernas, cansancio fácil, dificultad para subir gradas. Once enfermos (9\%) iniciaron la enfermedad con alteraciones en la emisión de orina (vejiga neurogénica). Veintidós (18\%) con molestias sensitivas poco sistematizadas, expresadas como ardor o pinchazos en la planta de los pies, sensación de frío o calor en las piernas, dolor profundo en la región tibial o rodilla; frecuentemente dolor lumbar, que es un síntoma inespecífico muy común. Además estas molestias sensitivas se presentaron repetida y variablemente en el curso progresivo de la paraparesia.

El examen clínico, definió un síndrome piramidal en el $100 \%$ de los pacientes, expresado por una respuesta extensora plantar en todos, hiperreflexia en extremidades inferiores en el 91,7\%, acompañado de disminución en la potencia muscular en las extremidades inferiores en el 98\% de los casos, con variable debilidad en los distintos grupos musculares. Los flexores de rodilla, psoas, glúteos y dorsiflexores de los pies estaban espe- 
cialmente afectados. El cuadriceps y flexor plantar tenían generalmente conservada su potencia. En las extremidades superiores no se encontró una significativa disminución de las fuerzas y sólo el 64\% tenía hiperreflexia. El reflejo mentoniano estaba exaltado en el $24 \%$ de los pacientes. La hipertonía espástica en reposo fue muy variable, generalmente intensa en los cuadros más clásicos $(50,4 \%)$, pero menos evidente en otros. En las extremidades superiores excepcionalmente se encontró hipertonía. El clonus de pie o rodilla estaba presente sólo en 39 pacientes (32\%).

Trastornos subjetivos de la sensibilidad como dolores y parestesias se encontró en treinta y siete pacientes $(30,5 \%)$. En quince enfermos (12\%) se definieron fallas de la sensibilidad profunda (sensación vibratoria). No se encontraron déficits de la sensibilidad termoalgésica. Ninguno de los enfermos mostró signos cerebelosos, ni se observó compromiso de los nervios motores bulbares, salvo cinco pacientes (4\%) que evolucionaron con un síndrome pseudobulbar.

En la primera evaluación clínica, setenta y tres pacientes $(60 \%)$ tenían una marcha tipo 2 (marcha espástica independiente), treinta y dos enfermos (26\%) mostraron una marcha tipo 3 (marcha paretoespástica con apoyo) y dieciséis (13\%) tenían una tipo 4 (bipedestación sin marcha). El $14 \%$ presentaba una marcha definida como inestable. Seguramente a causa de la debilidad muscular, alteraciones propioseptivas, o por una espasticidad asimétrica que expresaba un acortamiento mayor de los pasos en un lado, génesis de las lateropulsiones. Después de diez años de evolución, menos de la mitad conservó una marcha independiente. A los veinte años de enfermedad, menos del $20 \%$ mantenía una marcha independiente.

La vejiga neurogénica fue un componente habitual y generalmente precoz de la paraparesia espástica asociada a HTLV-I. En noventa y dos pacientes $(76 \%)$ se encontró algún compromiso de la función vesical, que en general evolucionó en paralelo con el compromiso motor. Inicialmente, el aumento de la frecuencia fue lo habitual, generalmente acompañada de nicturia. En la etapa intermedia se agregó la urgencia miccional, hasta llegar a la incontinencia. Sólo 29 pacientes (24\%) mostraron poco o ningún compromiso de la vejiga en los primeros cinco años. En treinta y siete enfermos (30,5\%) en los que se hizo estudio funcional de la vejiga, se encontró mayoritariamente una vejiga pequeña y una disarmonía entre el músculo detrusor y el esfínter externo, asociándose frecuentemente a una debilidad esfinteriana. No fue infrecuente que en aquellos pacientes en los que fallaba la relajación del esfínter externo, se produjera demora en el inicio de la micción y/o dolor con la emisión de orina.

La constipación es una condición frecuente en las paraparesias espásticas, sin embargo, un grupo de pacientes $(10,7 \%)$ mostró incontinencia intermitente del esfínter anal, presentando circunstancialmente deposiciones incontrolables.

Líquido cefalorraquideo: En todos los enfermos se realizó sistemáticamente el estudio del líquido cefalorraquideo (LCR). En el 33\% de los enfermos se observó una hipercelularidad linfocitaria que generalmente fue mínima, con un promedio de 10, 5 linfocitos ${ }^{6-50}$. La glucosa y la albúmina habitualmente fueron normales. Las bandas oligoclonales se mostraron alteradas en el $42,1 \%$ de los casos estudiados. El seguimiento, permitió la eventual repetición del estudio de LCR, observándose una tendencia a mantener el aumento de linfocitos en aquellos casos que lo tenían. El estudio de las metaloproteinasas en el LCR mostró aumento de MMP-9 en el 83\% de los pacientes estudiados, constituyéndose en un marcador de la actividad de reacción del parénquima nervioso a la degeneración axonal. Así también se apreció la disminución de la proteína tau total en el LCR y un particular aumento de la tau T181, que además estaba hiperfosforilada.

\section{Estudio neurofisiológico}

Los potenciales evocados somatosensoriales realizados en 57 pacientes, con el estimuló del nervio tibial posterior, observó anormalidades en 46 (81\%). Entre ellos en 24 pacientes hubo ausencia en la evocación de los potenciales, en los demás hubo aumento de la latencia. En 10, 
este aumento de la latencia estaba limitado al segmento medular. El estudio de potenciales evocados en las extremidades superiores, estimulando el nervio mediano, mostró aumento de la latencia sólo en 4 pacientes (9\%). Los potenciales visuales fueron normales en todos los enfermos, salvo en un caso. Ninguno de los pacientes sometidos a electromiografía y conducción nerviosa mostró alteraciones. En 29 pacientes se completó el estudio con termotest cuantitativo, observándose normalidad en los rangos de percepción de frío y calor. Sin embargo, en 25 enfermos se encontró sensación de calor paradojal en los pies, al estimular con frío.

\section{Estudio Neuroradiológico}

En las primeras etapas de la enfermedad, los estudios imagenológicos con Resonancia Magnética son habitualmente normales, tanto en la médula como en el cerebro. En general después del quinto año de paraparesia se comienza a observar una disminución del calibre de la médula dorsal. Ninguno de los pacientes muestra imágenes sugerentes de inflamación o desmielinización del parénquima nervioso. En una serie de treinta pacientes, en los que se realizó simultáneamente RM de cerebro y de la médula completa, se comprobó una atrofia leve, moderada o severa de la médula dorsal en el 61\% de ellos (Figura 1). Dos enfermas que mostraban una evolución superior a los veinte años, tenían también atrofia de la médula cervical, ambas pacientes carecían de un compromiso motor significativo en las extremidades superiores. Como la atrofia está ligada a la pérdida de fibras del haz cortico-espinal, la médula tiende a aplanarse en el sentido antero-posterior o toma un aspecto triangular con base anterior. La atrofia de la médula se ha relaciona significativamente con el tiempo de evolución y es concordante con la alteración de la marcha.

En el mismo estudio se observó que el 83\% de los pacientes tenían imágenes hiperintensas de la substancia blanca cerebral en las secuencias T2 y Flair, que no se modificaban con el medio de contraste. Mayoritariamente mostraron imágenes redondeadas de $5 \mathrm{~mm}$ o menos, ubicadas en áreas frontales. Sin embargo, nueve de estos pacientes tenían imágenes más extensas y parcialmente más tenues, distribuidas en la substancia blanca subcortical de áreas fronto-parietales (Figura 2) Este grupo con un compromiso más extenso de la substancia blanca cerebral coincidió con pacientes que cursaban con daño cognitivo.

En ninguno de los pacientes se encontró lesiones del cuerpo calloso, 1 mesencefálicas, periventriculares o cerebelosas, ni imágenes sugerentes de compromiso inflamatorio.

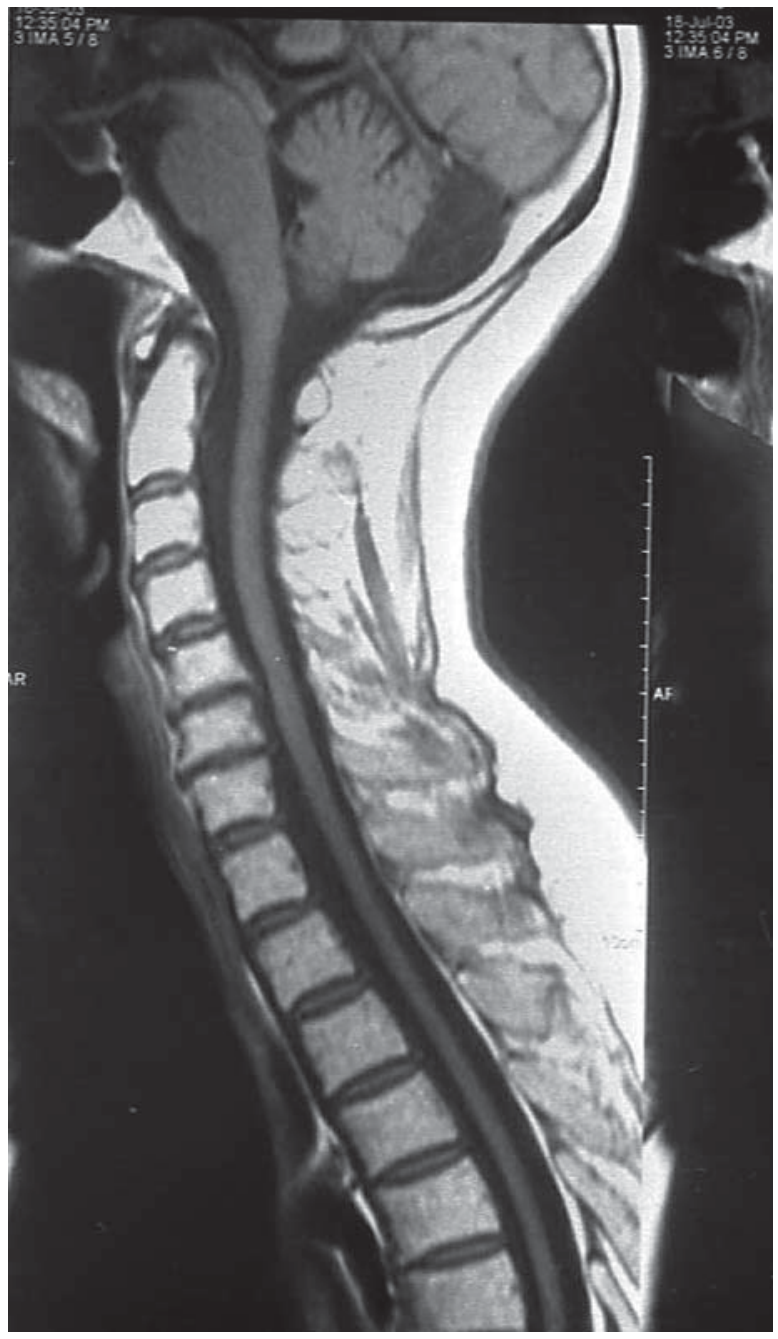

Figura 1. RM de médula cérvico-dorsal. Atrofia de la médula dorsal que expresa la pérdida de axones motores. En la RM de la paraparesia espástica HTLV-I, clásicamente no se observan cambios de intensidad en el parénquima de la médula espinal. 


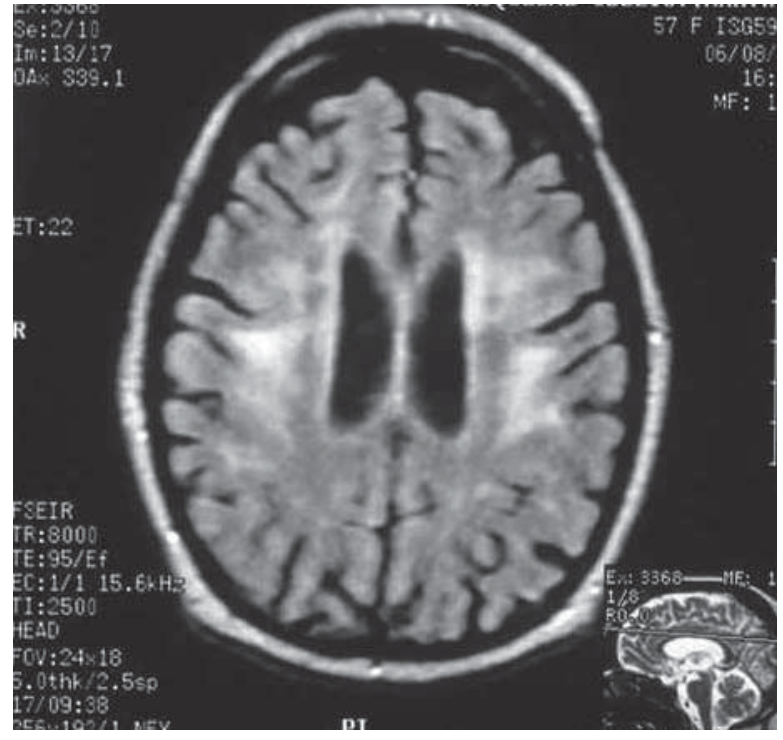

Figura 2. RM de cerebro (Flair). Areas de hiperintensidad subcorticales, bifrontales, que no toman el medio de contraste, expresión de un compromiso global del SNC en paciente con paraparesia espástica HTLV-I.

\section{Funciones cognitivas}

Fueron estudiadas regularmente en todos los enfermos, con WAIS y test de Retención Visual de Benton, dirigidos a establecer pérdidas cognitivas. En treinta y cinco pacientes (29\%) se demostró algún compromiso cognitivo. En ellos se definieron fallas de la memoria de corto plazo, déficit visocontructivo y de planificación. Se observó una relación significativa entre el progreso de la paraparesia y la disfunción cognitiva. En ese grupo de treinta y cinco pacientes más de la mitad mostró daño cognitivo moderado (57\%), y se observó un daño cognitivo mayor en el $11,4 \%$.

\section{Aspectos hematológicos}

Son muy importantes en pacientes que tienen infectados los linfocitos T. En algún momento de la evolución, el 75\% de los pacientes mostró linfocitos leucemoides con núcleos escotados o polilobulados. El hallazgo de estos linfocitos fue persistente en algunos casos, mientras en otros fue producto de una búsqueda circunstancial. La anomalía osciló entre el 1 y 2\% de los linfocitos, que en dos casos llegó al 10\%. Cinco pacientes de esta serie evolucionaron hacia un linfoma T (ATL) y en uno se definió una leucemia linfoide. Las lesiones cutáneas, en varios casos alertaron para el diagnóstico de linfoma.

\section{Marcadores inmunológicos}

$\mathrm{Su}$ búsqueda permitió establecer que no tenían una relación significativa con las patologías asociadas a HTLV-I. La presencia del factor reumático (FR) fue positiva en seis pacientes y sólo en dos se detectaron anticuerpos antinucleares elevados (ANA). Dentro de la serie, cuarenta y cinco enfermos tienen estudio de electroforesis de proteínas. En dieciséis (35,5\%), se observó aumento de la gammaglobulina sobre 1.500 y en tres un aumento no significativo de alfa 1 . El estudio de anticuerpos antitiroídeos mostró aumento en algunos enfermos, pero sin una significación estadística.

\section{Enfermedades asociadas}

El sindrome sicca se encuentra en al menos el $50 \%$ de las paraparesias asociadas a HTLV-I. A setenta y tres pacientes se les practicó el test de Schilmer, que se encontró positivo en 56 (77\%), menos de $10 \mathrm{~mm}$ de lagrimas en un minuto. Todos los pacientes que mostraron hipolacrimia fueron sometidos a biopsia de glándulas salivares menores, confirmándose el diagnóstico en 53 casos $(94,6 \%)$. El estudio histológico mostró cambios estructurales de los acinos y la presencia de infiltrados linfocitario (Figura 3a). Se observó predominio de linfocitos T (CD25) y se detectó la presencia de la proteína viral Tax del HTLV-I, tanto en los linfocitos $\mathrm{T}$, como en las células acinares de la glándula (Figura 3b). Sin embargo, sólo el 20,7\% de estos pacientes manifestó molestias clínicas del síndrome sicca, como ardor en los ojos, sensación de cuerpo extraño o sequedad de boca.

Daño hepático histológico se encontró en cinco pacientes, atribuible a hepatopatía por HTLV-I. La biopsia hepática y también el estudio necrópsico en dos casos, mostró un daño parenquimatoso variable y la presencia de linfocitos en el 
parénquima hepático (Figura 3c) constituida especialmente por linfocitos $\mathrm{T}(\mathrm{CD} 25)$ en áreas centrolobulillares. El estudio inmunohistoquímico detectó la presencia de la proteína Tax, tanto en los linfocitos como en las células hepáticas. (Figura 3d). La función hepática, estudiada rutinariamente, mostró en 17 pacientes sólo aumento de las fosfatasas alcalinas. Sólo tres pacientes cursaron con mayores e importantes déficits funcionales.

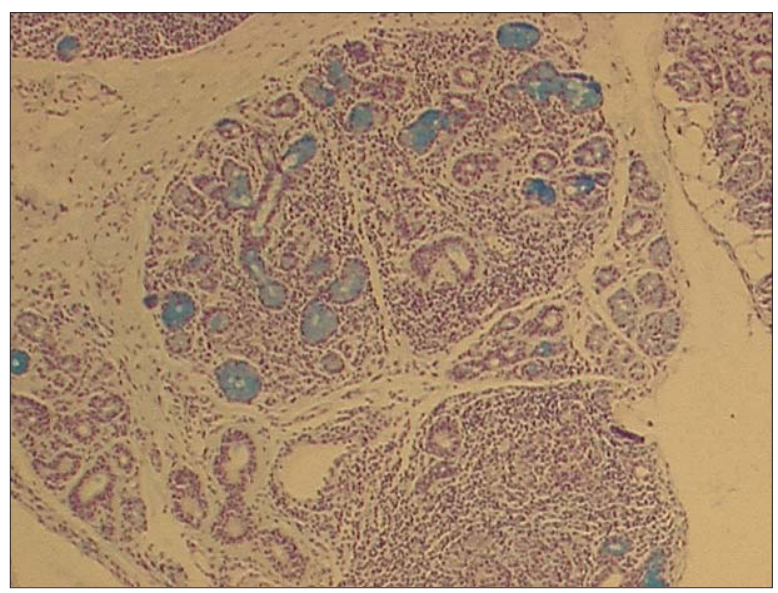

Figura 3a. Glándulas salivales que muestran infiltrados linfocitarios y pérdida de la estructura glandular ( HE y mucina $\mathrm{x} 100)$.

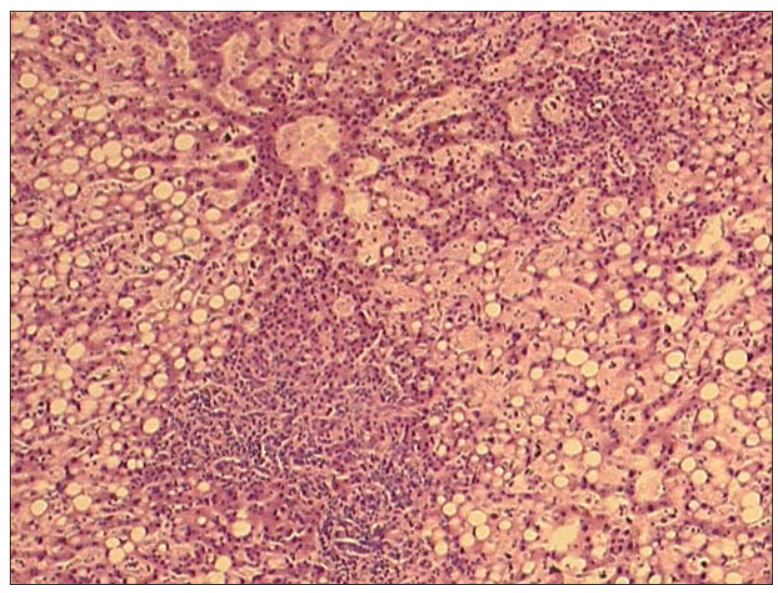

Figura 3c. Tejido hepático que muestra infiltrado linfocitario, en un paciente con paraparesia espástica (HE X 100).
Lesiones cutáneas aparecidas en el curso de su enfermedad se encontraron en el $28 \%$ de los pacientes. Se mostraron como lesiones eritematopapulosas morbiliformes distribuidas en las extremidades o el tórax, que generalmente mostraban un carácter transitorio de dos a seis semanas. También se observaron placas eritematosas en piernas o brazos que fueron más persistentes. Algunas adquirieron un carácter crónico y se transformaron en placas xerodérmicas descamativas, que se acom-

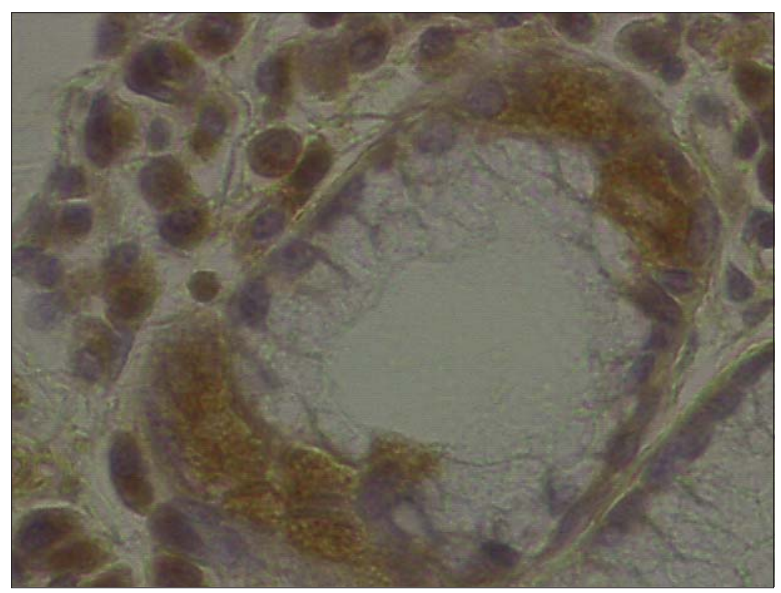

Figura 3b. Glándulas salivales teñidas para Tax, que muestran la presencia de la proteína viral en los linfocitos infectados y en células glandulares (anti-Tax x 200).

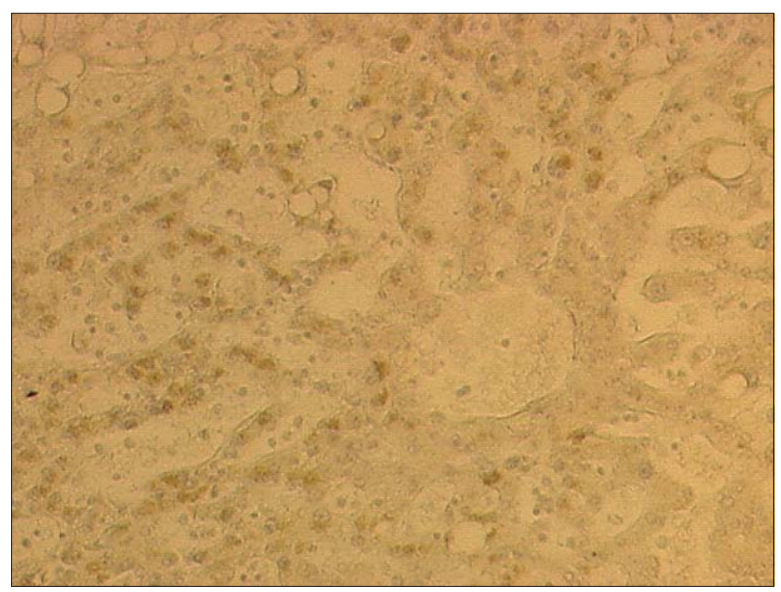

Figura 3d. Tejido hepático presencia de proteína Tax en linfocitos y células hepáticas (anti-Tax x 100). 
pañaron en algunos pacientes con sequedad generalizada de la piel. Veintiocho pacientes $(23,1 \%)$ han cursado con el diagnóstico de linfoma cutáneo. Histológicamente, la mayoría mostraron engrosamiento de la capa cornea e infiltrados dérmicos y epidérmicos llegando a formar en algunos casos abscesos de Paoutrier, que suelen caracterizar a los linfomas cutáneos.

Los Linfomas: Mostraron una evolución independiente del daño neurológico en nuestra serie, y no pareció que el proceso hematológico haya influido o interferido en la progresión del daño en el SNC. Los casos que cursaron con linfomas $\mathrm{T}$, con ganglios palpables inguinales, mediatínicos o mesentéricos, hepatoesplenomegalia en alguno, evolucionaron al ritmo de su linfoma.

La osteoporosis es un daño que se desarrolla precozmente en los pacientes infectados con HTLV-I, antes que el trastorno motor y la inmovilidad pudieran contribuir al fenómeno. El estudio con densimetría ósea, definida con ultrasonografía del calcáneo, realizado en 24 pacientes activos (con marcha independiente), demostró que ninguno de los pacientes tenían densimetrías normales. Entre las mujeres fue de $(-3,07)$, y en los hombres $(-2,93)$. El 29,2\% cumplía los criterios para osteopenia y el 70,8\% para osteoporosis.

La broncoalveolitis ha sido excepcional en esta serie, sólo 4 enfermos han cursado con bronquitis recidivante, con la esporádica presencia de infiltrados pulmonares, habitualmente interpretados como neumonitis. Sólo dos de estos pacientes fueron sometidos a estudios de cepillado bronquial en búsqueda del virus HTLV-I, con resultado positivo.

Polimiositis tenemos la descripción de un caso asociado con HTLV-I, parece un cuadro de excepción, entre nosotros.

La artritis también representó una excepción, aunque dolores en las grandes articulaciones son muy frecuentes en estos pacientes, pero sin cambios clínicos sugerentes de artritis. El dolor de caderas es particularmente relevante y frecuente.

Uveitis no se ha encontrado asociada a las paraparesias espásticas en Chile y al parecer tampoco primariamente vinculada al virus.
Neuropatía HTLV-I, tampoco se ha observado asociada a paraparesias o aisladamente.

\section{Hallazgos neuropatológicos}

Hasta el año 2005 sabíamos del fallecimiento de 20 pacientes. El promedio de años de evolución de la enfermedad hasta el fallecimiento fue de 15 años $(+7,2)$. Ocho pacientes fallecieron en la primera década de la enfermedad y doce en la segunda década. La causa más frecuente de muerte fue de origen infeccioso (pulmonar, urinario) en el 55\% de los casos, seguida de causas de carácter trombótico-embólico en el 25\% (embolias mesentérica, pulmonar e iliaca), La tercera frecuencia la ocupan las neoplasias (linfomas y cáncer vesical) $15 \%$.

Se logró el estudio neuropatológico en siete mujeres y cinco hombres.

Macroscópicamente los cerebros no mostraban alteraciones y tenían pesos de entre 1.100 y 1.420 gr. El 66\% de los casos mostraba atrofia de la médula espinal de predominio dorsal.

Con técnicas histológicas corrientes (HE, Luxol Fast-blue, Nissl) el estudio del cerebro no mostró cambios significativos, que incluyó una búsqueda particular en la corteza motora. Sin embargo, desde el bulbo raquídeo hacia distal, se encontró un daño sistematizado de la vía corticoespinal. En la mitad de los casos se observó adelgazamiento de las pirámides y/o palidez del haz corticoespinal a nivel bulbar.

En la médula espinal se apreció pérdida de axones y de mielina en el cordón lateral, particularmente de los segmentos dorso-lumbares (Figura 4a). En el cordón posterior solamente se observó una pérdida de la mielina en los fascículos del haz de Goll a nivel de la médula cervical (Figura $4 \mathrm{~b}$ ), que en los niveles dorso-lumbares estaba conservada (Figura 4a). La importante pérdida de axones del haz corticoespinal avalan la atrofia dorsal de la médula. La substancia gris de la médula espinal, no mostraba alteración significativa de las motoneuronas ni de otras estructuras celulares, aunque se apreciaba un definido aumento glíal.

Se observó engrosamiento de la leptomeninge 
y de la adventicia de los vasos, como consecuencia de una proliferación fibroblástica. No se encontraron cambios de la pared muscular ni del endotelio vascular, la luz de los vasos estaba conservada en todos los niveles del SNC. Algunos vasos meníngeos y del parénquima de la médula espinal presentaban manguitos de linfocitos (Figura 4c) constituidos principalmente por linfocitos $\mathrm{T}$ (CD4 y CD8), Esta presencia linfocitaria, ocasionalmente invadía el parénquima nervioso, especialmente en la substancia gris, que es más vascularizada. Sólo en la mitad de los pacientes

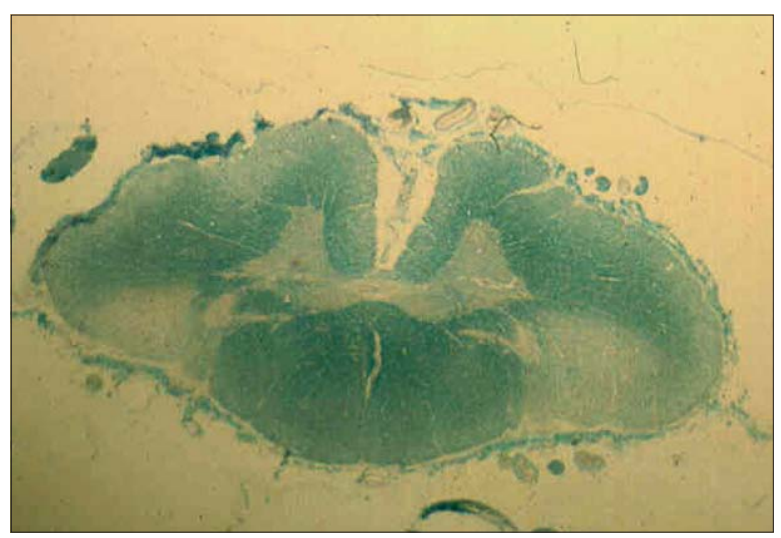

Figura 4a. Médula dorsal (D9) Muestra la pérdida de axones y la desmielinización en el cordón lateral del haz cortico-espinal originado por una axonopatía central (LFB X 4).

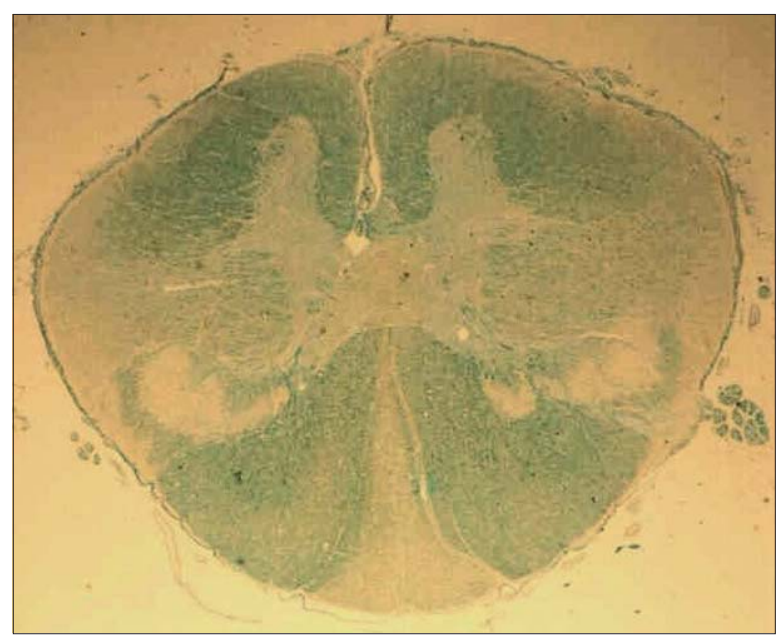

Figura 4b. Médula cervical (C2) Desmielinización selectiva del haz de Goll en el segmento distal de este haz sensitivo. Compromiso del haz cortico-espinal (LFB x4). se observó esta condición (Figura 4d).

El estudio inmunohistoquímico con antineurofilamentos, mostró la pérdida selectiva de axones en la vía corticoespinal (Figura 5a), así como la presencia de torpedos y dilataciones axonales (Figura 5b). Con anti-APP se encontraron depósitos de proteína precursora del amiloide (APP) en el cordón lateral y posterior, que denunciaban alteraciones del transporte axonal (Figura 5c). La anti-ubiquitina puso en evidencia pequeñas perlas de ubiquitina en el cordón lateral y también en la substancia blanca sub-

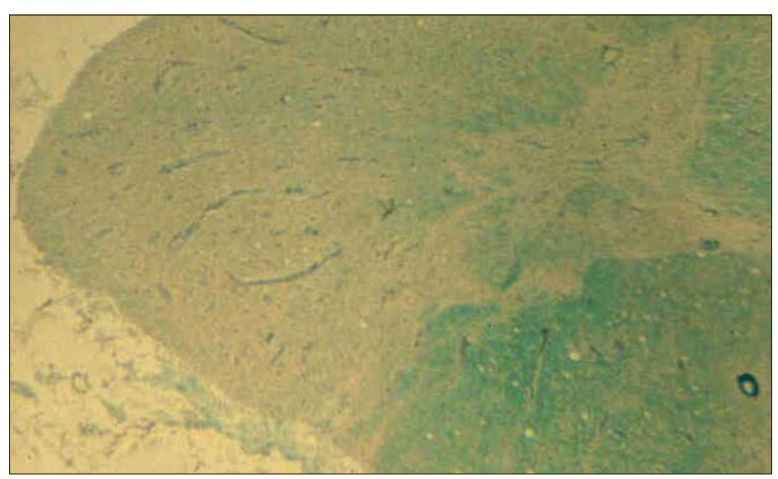

Figura 4c. Médula dorsal: Cordón lateral. Se observa engrosamiento de la adventicia de los vasos y la presencia de manguitos linfocitarios (LFB-Hematoxilina x10).

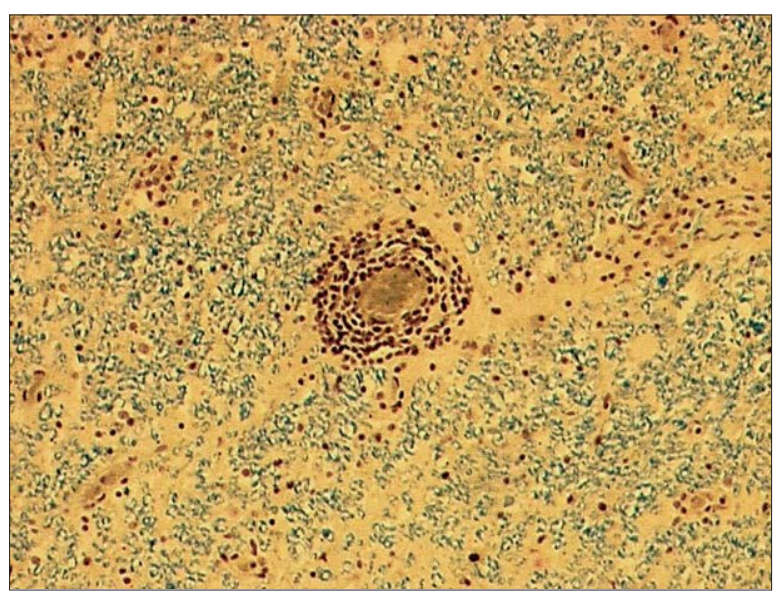

Figura 4d. Vaso de la médula espinal: Se observa un manguito linfocitario perivascular, sin alteraciones estructurales de carácter inflamatorio en la pared del vaso o del parénquima circundante (HE x100). 
cortical de las áreas motoras. También se observaron depósitos de proteína tau en los oligodendrocitos como se ha encontrado en algunas enfermedades degenerativas (Figura 5d). La tinción con GFAP mostró una proliferación glíal especialmente de los cordones laterales en las áreas degeneradas del haz corticoespinal. Los estudios con microscopia electrónica han definido mejor los cambios degenerativos de los axones de la vía corticoespinal. Se han observado ovillos de

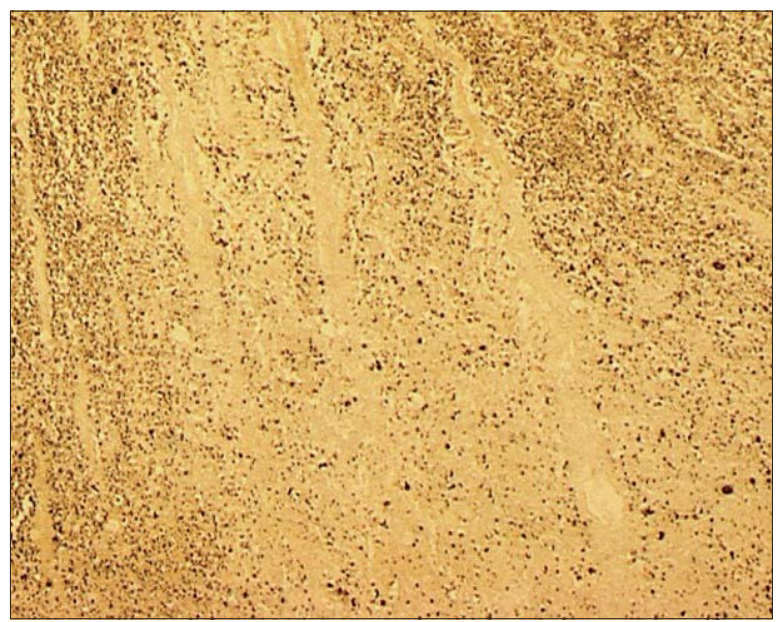

Figura 5a. Médula dorsal: Cordón latera, inmunohistoquímica para neurofilamentos. Se observa pérdida selectiva de neurofilamentos en el haz cortico-espinal (Antineurofilamentos x 100).

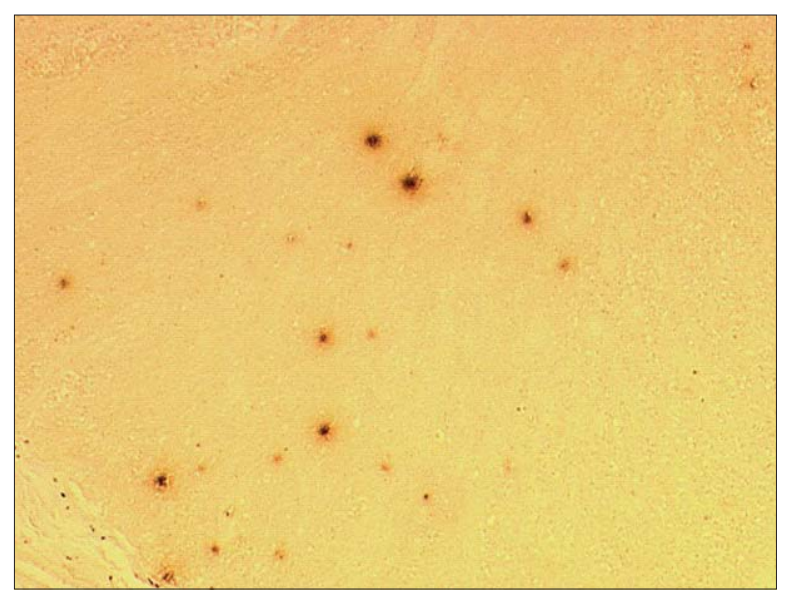

Figura 5c. Médula dorsal: Haz de Goll, inmunohistoquímica para identificar proteína precursora del amiloide (APP). Depósitos intra-axonales de APP que definen detención del flujo axoplásmico (Anti-APP x 50). neurofilamentos intraxonales y presencia de corpúsculos de Hirano. Así mismo cambios en la mielina consistentes en laminación de las vainas y separación entre el axón y la membrana del oligodendrocito, consecuencia del daño axonal, más que un compromiso desmielinizante primario.

El estudio histopatológico pudo establecer la selectividad de las lesiones degenerativas, que se localizaban particularmente en los largos axones espinales.

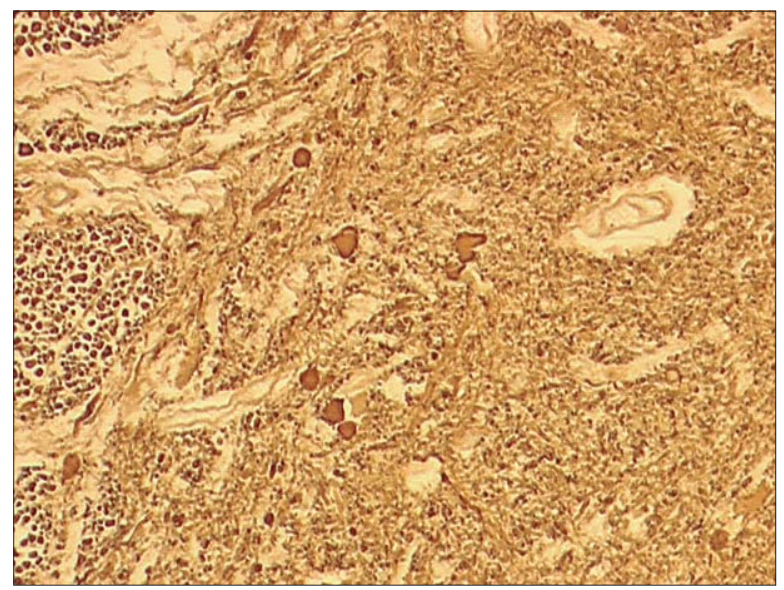

Figura 5b. Médula dorsal: Cordón lateral, inmunohistoquímica para neurofilamentos. Dilataciones axonales (torpedos) en el área de ingreso del haz cortico-espinal a la substancia gris (Antineurofilamentos x100).

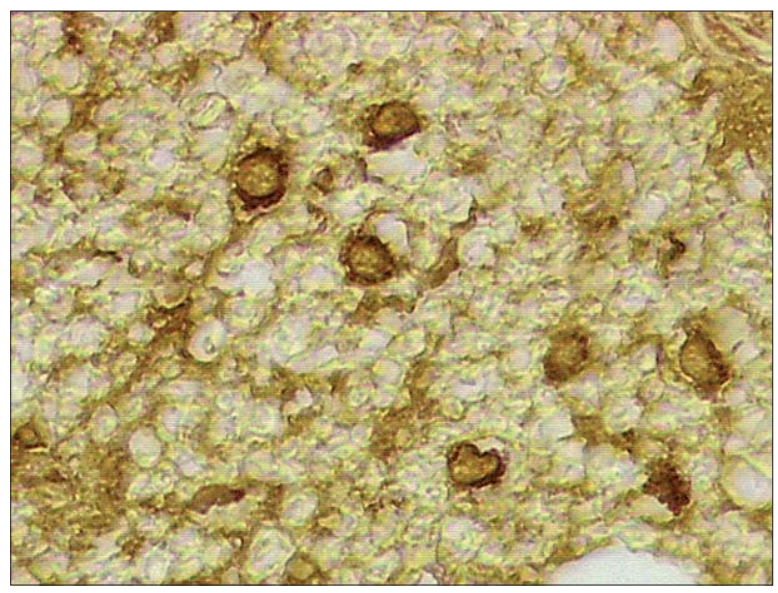

Figura 5d. Oligodendrocitos: Substancia blanca de la médula espinal. Inmunohistoquímica para proteína tau. Agregación de tau en el citoplasma de los oligodendrocitos, es sugerente de un proceso degenerativo. (Anti-tau x250). 


\section{Discución}

Los 121 pacientes con paraparesia espástica progresiva asociada a HTLV-I, seguidos por más de diez años, pusieron en evidencia que esta infección produce una enfermedad multisistémica. Que el daño neurológico se centra en la degeneración de los haces corticoespinales, debido a una alteraciones del transporte axoplásmico, más expresivo en los largos axones motores.

Desde un punto de vista clínico nuestra serie muestra amplias similitudes con la descrita por Nakagawa y colaboradores en $1995^{24}$. Coincidiendo en la edad de comienzo, los tiempos de evolución, las perturbaciones vesicales y alteraciones de la marcha, entre otros. Sin embargo, en nuestra serie la evolución lenta o rápida, no se relacionó con ningún parámetro biológico identificable, a diferencia de la serie japonesa que atribuye la velocidad de evolución al modo de infección. Asociando la evolución rápida a una infección por transfusión, similar al anecdótico caso reportado por Gout en $1990^{25}$, que describió un paciente con una paraparesia espástica aguda post-transfusional. En nuestra serie se incluyen casos de paraparesias asociado a transfusiones, cuya evolución no difiere de los demás casos, aunque al menos en dos pacientes la instalación de la enfermedad pareció ser rápida, sin que se modificara la evolución posterior. Por su parte, Cruickshank et $\mathrm{al}^{26}$, estudiaron 21 pacientes jamaicanos con una paraparesia espástica progresiva, que clínica y evolutivamente también son semejantes a los casos chilenos, aunque desde el punto de vista electrofisiológico aparecen diferencias. En las paraparesias jamaicanas 11/19 tenía alterado los potenciales evocados visuales. En nuestros pacientes las alteraciones neurofiológicas se limitan al enlentecimiento de los potenciales evocados somatosensoriales, en el $81 \%$ de los pacientes ${ }^{27}$.

En otras series y con un número pequeño de caso, se encontró compromiso periférico. Se han descrito mononeuritis múltiple, neuropatías desmielinzantes crónicas y degeneraciones axonales $^{28-30}$. Los pacientes chilenos no tienen compromiso periférico y es probable que estas comu- nicaciones se deban a una asociación casual del virus, a susceptibilidades étnicas, o a la eventual infección por cepas virales distintas.

Entre nuestros pacientes la RM ha mostrado una progresiva atrofia de la médula dorsal y nunca lesiones de aspecto inflamatorio. Además, en la mayoría de los enfermos generalmente después del quinto año de enfermedad, se han observado lesiones en la substancia blanca del centro oval y subcorticales, que son hiperintensas en T2 y Flair y que no captan contraste ${ }^{31}$. Estos cambios de la substancia blanca ya habían sido estudiados por Kira 1991 y Ferraz $1997^{32,33}$, imágenes que ellos calificaron como leucoencefalopáticas y que en el trabajo de Ferraz son contemporáneas con la atrofia de la médula dorsal, como en nuestros $\operatorname{casos}^{31}$. La ausencia de lesiones inflamatorias en otras áreas cerebrales, la clínica y la serología positiva para el virus permiten identificarlas como la expresión de una patología asociada al HTLV-I y establecer la diferencia con formas de esclerosis múltiple ${ }^{34}$. Aunque recientemente han sido descritas mielopatías HTLV-I, con neuroimágenes de la médula espinal en todo semejantes a las mielitis transversas ${ }^{35}$.

Las leucoencefalopatías HTLV-I suelen asociarse a compromiso cognitivo, con las características clínicas de los daños subcorticales. En algunos pacientes la amplitud de las lesiones de la substancia blanca del centro oval evolucionan a una demencia, como los casos de Ogata 1993, Lycke 1993 y Cartier 199936-38. Sin embargo, la gran mayoría de los pacientes HTLV-I con daño cognitivo sólo expresan alteraciones moderadas de la memoria, compromiso viso-constructivo y defectos de las funciones ejecutivas, que avalan una desconexión parcial frontobasal en el contexto de una enfermedad fundamentalmente motora $^{39}$. Silva y cols, hicieron una excelente evaluación del compromiso cognitivo de estos pacientes, confirmando que el daño que origina el HTLV-I compromete todo el SNC ${ }^{40}$.

Los estudios inmunohistoquímicos de la médula espinal definen un compromiso específico de los largos axones motores y sensitivos. Estableciendo que la degeneración selectiva, inicial- 
mente distal de estos axones, está vinculada a la presencia de depósitos de APP, señal inequívoca de una alteración del transporte axoplásmico ${ }^{41-42}$. Estos hallazgos se ven corroborados por el estudio con microscopia electrónica, que sólo muestran cambios degenerativos de los axones y de la mielina ${ }^{43}$.

Es interesante remarcar la presencia del virus en las glándulas exocrinas, especialmente en las glándulas mamarias, que es un reconocido factor de riesgo en las infecciones por lactancia ${ }^{41}$. Así como el daño en las glándulas lagrimales, salivales y sudoríparas, origen de la dacrosialopatía y el síndrome sicca que está presente en más del $50 \%$ de los pacientes de nuestra serie ${ }^{42}$. Menor prevalencia del síndrome fue observada por Nakagawa y antes por Vernant ${ }^{24,43}$. Esta forma viral del síndrome sicca, se diferencia claramente del Síndrome de Sjögren (SS) primario, porque carece de los marcadores Ro y La, que lo identifican. Tampoco muestra elementos clínicos o serológicos que lo vinculen a una colagenopatía, que define al SS secundario ${ }^{42}$. La reacción linfocitaria de las glándulas salivares, sería una respuesta a la presencia del HTLV-I, como lo demostró experimentalmente Greens $1989^{44}$. Esta dacrosialopatía se vincularía a la infección de las glándulas por el virus y a la presencia de la proteína Tax en los acinos glandulares ${ }^{45,46}$. También es significativo el daño hepático, que puede ser inaparente o relevante según el caso, y que se identifica por la presencia de linfocitos infectados y de proteína Tax en las células del parénquima hepático ${ }^{45}$. Ijichi en 1993, ya había observado el daño hepático silencioso por HTLV-I, como el ocurrido en alguno de nuestros enfermos ${ }^{47}$. Los cambios linfomatosos de la piel, definidos como micosis fungoide, acompañó casi a un cuarto de nuestros pacientes. Que en algunos casos se definió como un síndrome de Sésary. Tan alta incidencia de cambios linfomatosos asociados a la paraparesia no está descrita en otras series ${ }^{24,26}$.

La artritis, y la broncoalveolitis son infrecuentes entre nosotros a diferencia de otros ${ }^{48,49}$, así como la polimiositis por HTLV-I. Hemos observado sólo un caso de polimiositis primaria aso- ciada al virus ${ }^{50}$ y no la hemos encontrado asociada a las paraparesias, habiéndola buscado. Nuestra serie difiere de lo descritos en Jamaica y las Antillas donde se han presentado numerosos casos de polimiositis asociadas a HTLV- $\mathrm{I}^{51,52}$, que también se han observado aunque en menor número en Japón ${ }^{53}$. Estas diferencias en la expresión de las enfermedades por HTLV-I, hace presumible la intervención de factores tanto étnicos como virales.

Las paraparesias espásticas, al igual que las enfermedades vinculadas al HTLV-I han soportado permanentemente hipótesis patogénicas inmunológicas o inflamatorias. Estas hipótesis están basadas en la apariencia inflamatoria que muestran los tejidos, debido a la presencia de linfocitos activados, aunque en el SNC no se encuentren evidencias de un daño parenquimatoso de carácter inflamatorio, salvo la presencia de linfocitos perivasculares. Esta condición también llamó la atención de Iwasaki que encontró vasos rodeados de linfocitos en áreas que no mostraban lesiones del parénquima nervioso ${ }^{54}$. La expresión de citoquinas en estos linfocitos perivasculares fue el argumento que hizo surgir la hipótesis de una respuesta inflamatoria, aunque el daño tisular no correspondía a un proceso inflamatorio y era degenerativo y de carácter sistematizado, afectando un grupo específico de fibras $^{55-57}$. La presencia de linfocitos en todos los tejido, se debe al aumento de su número y al de su capacidad adhesiva, que facilita la adherencia de los linfocitos entre si, permitiendo el traspaso del virus. Junto al aumento del factor de adhesión celular, está el aumento del factor de adhesión vascular ${ }^{58}$, que secundariamente permite la infección del endotelio vascular, debido a la existencia en las células endoteliales de receptores Glut-1 y Neuropilin-1, recientemente identificados en ellas, que permitirían el ingreso del virus a las células endoteliales. La infección de estas células origina la inhibición en la producción de la proteína selladora de los espacios intercelulares, posibilitando la alteración de la barrera hematoencefálica ${ }^{59}$. Sin embargo, no se ha encontrado la presencia del virus en el tejido nervioso ${ }^{60}$. 
La génesis de proteína Tax por los linfocitos CD4 infectados, resulta ser el determinante mayor en la persistencia de la infección y es la causa de la transformación de los linfocitos $\mathrm{T}$, favoreciendo su activación y proliferación, pudiendo llevarlos a la transformación linfomatosa. La capacidad de acción de Tax en los distintos tejidos y receptores, hace presumible la intervención de esta proteína viral en el origen de las distintas patologías ${ }^{61}$.

Experimentalmente se ha demostrado una interacción de la proteína Tax del HTLV-I con los neurofilamentos. Tax se ligaría a la internexina que es una de las proteínas estructurales de los neurofilamentos ${ }^{62}$. En el LCR de pacientes con paraparesia espástica progresiva, se ha observado la presencia de la Treonina 181 hiperfosforilada, un ligando de la proteína tau, cuya alte- ración podría comprometer el transporte axonal ${ }^{63}$. Asimismo, la activa presencia de Tax en el líquido cefalorraquideo (espacio extracelular), sería capaz de modular las respuestas de la matriz-extracelular de las neuronas por su conocido efecto activador o inhibidor sobre distintos receptores $^{64,65}$. Entre ellos activa la expresión de las metaloproteinasas, particularmente de MMP9 y de sus inhibidores, que se originan en neuronas y glía ${ }^{66,67}$.

Aún no está completamente esclarecida la patogenia de la paraparesia espástica ligada al HTLV-I. Sólo se ha establecido que se trata de una axonopatía central que muestra una alteración del transporte axoplásmico, y produce una degeneración axomielínica, que preferentemente afecta los axones más largos (haz corticoespinal), aunque siempre compromete todo el SNC.

\section{Resumen}

Se revisan las paraparesias espásticas progresivas del adulto (PEPAs) producidas por el HTLVI, en 121 pacientes chilenos. Se analizan los aspectos epidemiológicos, clínicos, diagnósticos, las enfermedades asociadas, y la patogenia. El seguimiento de los pacientes durante varios años permitió definir el perfil evolutivo, establecer las causas de muerte y estudiar el comportamiento del virus. De los casos con anatomía patológica surgieron hipótesis, que han permitido definir mecanismos de daño, sustentados en estudios inmunohistoquímicos. Se pudo confirmar que la enfermedad del SNC es un proceso degenerativo, vinculado a una axonopatía central que expresa fallas del transporte axoplásmico, que afecta particularmente la vía corticoespinal, aunque existe un compromiso más extenso mielo-encefálico. Además, el virus es capaz de producir una enfermedad multisistémica, que puede comprometer simultáneamente el sistema nervioso, el sistema hematológico, las glándulas exocrinas, el parénquima hepático, pulmonar, muscular y óseo.

Palabras clave: Paraparesia espástica tropical, HTLV-I, axonopatía central. Transporte axoplásmico. 


\section{Referencias}

1. Poiesz B J, Ruscetti F W, Gazdar A F, Bunn P A, Minna J D, Gallo R C. Detection and isolation of type $\mathrm{C}$ retrovirus particles from fresh and cultured lymphocytes of a patient with cutaneous T-cell lymphoma. Proc Natl Acad Sci U S A 1980; 77 (12): 7415-9.

2. Gessain A. Barin F, Vernant J C, Gout O, Calender A, De The G. Antibodies to Human T-lymphotropic Virus in patients with tropical spastic paraparesis Lancet 1985; U: 407-10.

3. Cartier L, Mora, Araya E, Castillo J L, Verdugo R, et al. HTLV-l Positive spastic paraparesis in a temperate zone. Lancet 1989; 1: 556-60.

4. Vásquez P, Sánchez G, Volante C, et al. Human T lymphotropic virus type 1: New risk for Chilean population. Blood 1991; 78: 850-51.

5. Cartier L, Cartier E. HTLV-l-ll in Chile, in HTLV, Truths and questions. Edt. Zaninovic V., Cali Colombia 1996; 150-8.

6. Cartier L, Tajima K, Araya F, Castillo J L, Zaninovic V, Hayami M, et al. Estudio preliminar de Seroprevalencia de HTLV-I en población Indígena Chilena. Rev Méd Chile 1993; 121: 241-6.

7. Miura T, Yamashita M, Zaninovic V, Cartier L, Takashima J, Igarashi T, et al. Molecular Phylogeny of Human T-cell Leukaemia virus type I and II of Amerindians in Colombia and Chile. J Molecular Evolution 1997; 44 (suppl 1): S76-S82.

8. Fujiyoshi T, Li H C, Lou H, et al. Characteristic distribution of HTLV Type 1 and HTLV Type II carriers among native ethnic groups in South America. AIDS Res and Human Retroviruses 1999; 15 (14): 1235-9.

9. Cartier L. Epidemiología de la infección por HTTLV-I/HTLV-II en el continente americano. En: Retrovirus linfotropos humanos: Aspectos epidemiológicos y clínicos de la infección por HTLV-I/ II. Editores: Calderón E, Matutes E, Soriano V.ENE. Madrid 1998; 3: 41-6.

10. Li H C, Fujiyoshi T, Lou H, Yashiki S, Sonoda S, Cartier L, et al. The presence of ancient human Tcell Lymphotropic virus type I provirus DNA in an Andean mummy. Nature Medicine 1999; 12: 142832.
11. Ramírez E, Cartier L, Villota C, Fernández J. Genetic characterization and phylogeny of human T-cell lymphotropic virus type I from Chile. Virus Research 2002; 84v1-2: 135-49.

12. De Castro Costa C M, Goubau P, Liu H F, et al. HTLV-Negative and HTLV type 1-Positive tropical spastic paraparesis in North-eastern Brazil AIDS research and H. Retroviruses 1995; 11 (2): 315-8.

13. Gracia F, Castillo L C, Larreategui M, Roberts B, Cerdeño V, Heneine W, et al. Relation between Human T-Lymphotropic virus type I and neurological disease in Panama 1985-1990. AIDS Research and Human Retroviruses 1995; 1-6.

14. Cartier L, Vergara C, Ramírez E, Casivar T, Vásquez S. Seroprevalencia del HTLV-I en familiares de pacientes con paraparesias espásticas. Rev Méd Chile 1995; 123: 7-11.

15. Cartier L, Ramírez E, Galeno H. Familial form of tropical spastic paraparesis report of four families. Rev Méd Chile 1998; 126: 419-26.

16. Osame M, Janssen R, Kubota H, et al. Nationwide survey of HTLV-I associated myelopathy in Japan: Association with blood transfusion. Ann Neurol 1990; 28: 50-6.

17. Arango C, Concha M, Zaninovic V. Epidemiology of tropical spastic paraparesis. Ann Neurol 1988; 23 (suppl 1): 161-5.

18. Zaninovic V, Sanzón F, López F. Geographic independence of HTLV-I and HTLV-II foci in the Andes Highland, the Atlantic coast and the Orinoco Colombia. AIDS Res. Human Retroviruses 1993; 10: 97-101.

19. Takezaki T, Tajima K. Epidemiology of ATLL and HAM/TSP in Asia; HTLV-l in Truths and questions. Ed. Zaninovic U. Cali-Colombia 1996; 66-77.

20. Souther S O, Souther P J. Persistent HTLV-I infection of breast luminal epithelial cells. A role in HTLV-I transmission. Virology 1998; 241: 200-14.

21. Galeno H, Ramírez E, Cartier L. HTLV-I Provirus in seronegative Chilean patients with tropical spastic paraparesis. Lancet 1996; 348: 1170.

22. Ramírez E, Cartier L, Ríos M, Fernández J. Defective human $\mathrm{T}$ cell Iymphotropic virus type 1 (HTLV-l) Provirus in seronegative patients with tropical spastic paraparesis or HTLV-I myelopathy. J Clinical Microbiology 1 998; 36: 1811-3. 
23. Cartier L, Ramírez E, Galeno H. El gen "tax" del virus linfotrópico humano tipo I en la identificación etiológica de la paraparesia espástica tropical: Estudio clínico, serológico y de polimerasa en cadena en 72 pacientes. Rev Méd Chile 1999; 127: 945-52.

24. Nakagawa M, Izumo S, ljichi S, et al. HTLV-I associated myelopathy: analysis of 213 patients based on clinical features and laboratory findings. Journal of neurovirology 1995; 1: 50-61.

25. Gout O, Baulac M, Gessain A, et al. Rapid development of myelopathy after HTLV-I jinfection acquired by transfusion during cardiac transplantation. N England J of Med 1990; 322 (8): 3838.

26. Cruickshank J K, Rudge P, Dalgleish A G, Newton $\mathrm{M}, \mathrm{Mc}$ Lean, et al. Tropical spastic paraparesis and human T-cell lymphotropic virus type 1 in the United Kingdom Brain 1989; 112: 1057-90.

27. Castillo J L, Cartier L, Araya F, Verdugo R, Mora C, Gibb C. Evoked potential abnormalities in progressive spastic paraparesis associated to HTLVI. Acta Neurol Scand 1991; 83: 151-4.

28. Said G, Lacroix C, Fujimura H, et al. The Peripheral Neuropathy of Necrotizing Arteritis: A Clinopathological Study Ann Neurol 1988; 23: 461-5.

29. Sugimura K, Takahashi A, Watanabe M, et al. Demyelinating changes in sural nerve biopsy of patients with HTLV-l-associated myelopathy. Neurology 1 990; 40: 1263-6.

30. Bhijee A L, Biel P L, Wiley C A, Windsor I M, Matthias D A, Amenomori T, et al. Peripheral nerve lesions in HTLV-I associated myelopathy. (HAM/ TSP). Muscle Nerve 1993; 16: 21-6.

31. Cervilla J, Cartier L, García L. Resonancia magnética de médula espinal y cerebro en el correlato clínico de la paraparesia espástica progresiva que se asocia al virus humano linfotrópico tipo I. Rev Méd Chile 2006; 134: 1010-8.

32. Kira J, Fujihara K, Itoyama Y, Goto I, Hasuo K. Leukoencephalopathy in HTLV-I associated myelopathy /tropical spastic paraparesis MRI analysis and a tow year follow up study after corticosteroid therapy. J. Neurol Sciences 1991; 160: 41-9.

33. Ferraz A C, Gabbai A A, Abdala N, Gomes R.
Ressonancia Magnética na mielopatia associada ao HTLV-I Leucoencefalopatia e atrofia medular. Arq Neuropsiquiatr 1997; 55: 728-36.

34. Stevenson V L, Miller D H, Rovaris M, Barkhof F, Brochet B, Dousset V, et al. Primary and transitional progressive MS. A clinical and MRI crosssectional study. Neurology 1999; 52: 839-45.

35. Umehara F, Nose H, Saito M, Fukuda M, Ogino $\mathrm{M}$, Toyota $\mathrm{T}$, et al. Abnormalities of spinal magnetic resonance images implicate clinical variability in human T-cell lymphotropic virus type I-associated myelopathy. Journal of NeuroVirology 2007; 13: 260-7.

36. Ogata A, Nagashima K, Tashiro K, Miyakawa A, Mikuni C. MRI pathological correlate of brain lesions in a necropsy case of HTLV-I associated myelopathy. J Neurol Neurosurg Psychiatry 1993; 56: 194-6.

37. Lycke J, Svennerholm B, Svenningsson A. Pssjble assocjation of HTLV-I infection and dementia. Acta Neurol Scand 1993; 88: 199-203.

38. Cartier L, Gormáz A, Kleinsteuber K, Ramírez E, Galeno H. New form of subcortical dementia: encephalopathy due to infection with human lymphotropic T virus (HTLV-I). Rev Méd Chile 1997; 125 (2): 209-13.

39. Cartier L, Gormaz A. Demencia subcortical en paraparesia espástica tropical asociada a HTLV-I: Estudio de 43 casos. Rev Méd Chile 1999; 127: 44450.

40. Silva MTT, Matos P, Alfaro A, Araujo AQ-C. Neuropsychological assessment in HTLV-1 infection: A comparative study among TSP/HAM, asymptomatic carriers, and healthy controls. J Neurol Neurosourg Psychiatry. 2003; 74: 1085-9.

41. Souther S O, Souther P J. Persistent HTLV-I infection of breast luminal epithelial cells: A role in HTLV transmission. Virology 1998; 241: 20014.

42. Cartier L, Castillo J L, Cea J G, Villagra R. Chronic dacrosyalpadenitis in HTLV-l associated myelopathy. J Neurol Neurosurg Psychiatry 1995; 58: 244-6.

43. Vernant J C, Buison G, Magdeleiene J, De Thore J, Jonannelle A, Neisson-Vernant C, et al. Tlymphocyte alveolitis, Tropical spastic paraparesis 
and Sjögren syndrome. Lancet 1988; i: 177.

44. Green J E, Hinrichs S H, Vogel J, Jay G. Exocrinopathy resembling Sjögren's syndrome in HTLV1 tax transgenic mice. Nature 1989; 34: 72-4.

45. Cartier L, Vergara C, Ramírez E. Proteína Tax (HTLV-I) probable factor patogénico y marcador del síndrome sicca que se asocia al HAM/TSP. Rev Méd Chile 2005; 133: 1183-90.

46. Beby-Defaux A, Frugier E, Bourgoin A, et al. Nucleotide sequence analysis of human T-Cell lymphotropic virus type $1 \mathrm{pX}$ anci LTR regions from patients with sicca syndrome. J of Med Virology 1999; 59: 245-55.

47. Ijichi T, Miyata K, Man S, Tsuchihashi Y. Asymptomatic primary biliary cirrhosis in HTLV1 associated myelopathy. Am J Gastroenterology 1993; 88 (12): 21 07-9.

48. Caudec L, Cauberrere I, Venet A. Alveolite lymphocytair et myelopathie assocIee au virus HTLV-I. Retrovirus 1990; 6: 109-13.

49. Higashiyamu Y, Katamine S, Kolmo S. Expression of Human T Lymphotropic virus type I (HTLV-I) tax/rex gene in fresh brocho- alveolar lavage cells of HTLV-I infected individuals. Clin Exp Inmunol 1994; 96: 193-201.

50. Cartier L, Prina L. Polymyositis associated to HTLV-l infection. Rev Méd Chile 1996; 124: 461-4.

51. Sherman M, Amin R, Rodegers-Johnson P, et al. ldentification of human $\mathrm{T}$ cell leukemiallymphoma virus type 1 antibodies, DNA protein in patients with polymyositis. Arthritis \& Rheumatism 1995; 5: 690-8

52. Smadja D, Bellance R, Cabre P, et al. Atteintes du systéme nerveux périphérique et du muscle squelettiqüe au cours des paraplégies associées au virus HTLV-I. Rev Neurol 1995; 151(3): 190-5.

53. Higushi 1 , Hashimoto $\mathrm{K}$, Kashio $\mathrm{N}$, et al. Detection of HTLV-I provirus by in situ polymerase chain reaction in mononuclear inflammatory cells in skeletal muscle of viral carriers with polymyositis. Muscle \& Nerve 1995; 18: 854-8.

54. Lwasaki Y. Pathology of chronic myelopathy associated with HTLV-l infection (HAM/TSP) J. Neurol Scien 1990; 96: 103-23.

55. Jacobson S, Zaninovic V, Mora C, et al. lmmunological findings in neurological diseases associated with antibodies to HTLV-I: Activated lymphocytes in tropical spastic paraparesis. Ann Neurol 1988; 23: S196-S200.

56. Umehara F, Izumo S, Ronquillo A T, Matsumuro $\mathrm{K}$, Sato E, Osame M. Cytokine expression in the spinal cord lessions in HTLV-l associated myelopathy J.Neuropathol Exp Neurol 1994; 53: 72-7.

57. Umehara F, Izumo S, Nakagawa M, Ronquillo A $\mathrm{T}$, Takahashi K, Matsumuro K, et al. Immunocytochemical analysis of the cellular infiltrate in the spinal cord lessions in HTLV-l associated myelopathy. J Neuropathol Exp Neurol 1993; 52: 424-30.

58. Umehara E, Izumo S, Takeya $\mathrm{M}$, et al. Expression of adhesion molecules and monocyte chemoattractant protein-1 (MCP 1 in the spinal cord lesions in HTLV-1 associated myelopathy. Acta Neuropathol 1996; 91: 343-50.

59. Afonso P V, Ozden S, Cumont M C, Seilhean D, Cartier L, Payam R, et al. Alteration of BloodBrain Barrier integrity by retroviral infection. Plos Pathogens 2008; 4: 1-11.

60. Tangy F, Vernant J C, Coscoy L, Ossondo M, Ballance R, Zaninovic V, et al. A search for Human T-Cell leukemia virus type I in the lesions of patients with tropical spastic paraparesis and polymiositis. Ann Neurol 1995; 38: 454-60.

61, Boxus M, Twizere J C, Legros S, Dewulf J F, Kettmann R, Willems L. The HTLV-I Tax interactome. Retrovirology 2008 ; 5: 76: 1-24.

62. Reddy T R, Li X, Jones Y, Ellisman M H, Ching G Y, Liem R K, et al. Specific interaction of HTLV Tax protein and human type IV neuronal intermediate filament protein. Proc Natl Acad Sci USA 1998; 95: 702-7.

63. Maldonado H, Ortiz-Riaño E, Krause B, Barriga A, Medina F, Pando M E, et al. Microtubule proteins and their posttranslationally forms in cerebrospinal fluid of patients with paraparesis associated to HTLV-I infection and in SH-SY5Y cells, and in vitro model of HTLV-I induced disease. Biol Res 2008; 41: 239-52.

64. Cartier L, Ramírez E. Presence of HTLV-I Tax protein in cerebrospinal fluid from HAM/TSP patients. Archives Virol 2005; 150: 743-53. 
65. Ramírez E, Cartier L, Torres M, Barría M. Temporary dynamics of human t-lymphotropic virus type I tax mRNA and proviral DNA load in peripheral blood mononuclear cells of human $\mathrm{T}$ lymphotropic virus type I-associated myelopathy patients. J Med Virol 2007; 79: 782-90.

66. Giraudon R, Szymocha R, Buart S, Bernard A, Cartier L, Belin M F, et al. T Lymphocytes activated by persistent viral infection differentially Modify the Expression of metalloproteinases (MMPS) and their endogenous inhibitors, TIMPs, in Human Astrocytes: relevance to HTLV-I induced neurological disease. Journal of Immunology 2000; 164: 2718-27.

67. Valenzuela M A, Collados L, Kettlun A M, González $\mathrm{R}$, Cartier L. Increased activity of matrix metalloproteinases and their tissue inhibitors in cerebrospinal fluid of patients with HTLV-I associated tropical spastic paraparesis. Rev Méd Chile 2000; 128: 585-92.

Correspondencia:

Luis Cartier, M.D.

E-mail: 1cartier@med.uchile.cl 